\title{
Seguridad militar reactiva o políticas humanas integrales, el eterno dilema en América Latina
}

\section{Sugerencia de citación:}

Brocate Pirón, R. (2017). Reseña. Seguridad militar reactiva o políticas humanas integrales, el eterno dilema en América Latina. Razón Crítica, 2, 163-171.

Reseña del libro:

Ríos Sierra, Jerónimo; Benito Lázaro, Miguel M., y Castillo Castañeda, Alberto (Coords.) 2015. La arquitectura de la violencia y la seguridad en América Latina. Madrid, Editorial La Catarata, 271 pp. ISBN: 978-84-9097-032-4. 
Esta obra cartografía las metodologías de conflicto asimétrico más recientes de una región en continua ebullición. Dichas formas de conflicto distan de las tradicionales guerras y, de una manera kaldoriana se apunta a la presencia de conflictos sociales intraestatales, más que entre Estados-nación. La América Latina que surge del sistema post-hegemónico norteamericano relaciona de manera sutil la mercantilización y liberalización económica de la región con altos índices de pobreza, desequilibrios sociales y violencia.

Esta obra revela cómo América Latina ya no cuenta con amenazas exteriores de gran calado, sino que más bien se enfrenta a un problema de autoridad y legitimidad interna y se ve expuesta a riesgos y amenazas que debilitan los Estados-nación desde el interior. Problemas sistémicos y endémicos, tales como, fragilidad democrática, corrupción, crimen organizado, falta de seguridad judicial, carencia de estrategias de desarrollo sostenibles, altos niveles de desempleo, economía informal, coadyuvados por una pobreza extrema y altos niveles de pobreza, refrendan un status quo de inseguridad en la región más violenta del mundo.

Los altos niveles de violencia y desigualdad de Centroamérica y el norte de Sudamérica contrastan con unos niveles menores de inseguridad en el Cono Sur del continente. Los niveles de inseguridad y violencia de Chile, Uruguay, Argentina o Paraguay distan del centro y norte de Sudamérica y de países como Brasil, Colombia o Venezuela.

Siguiendo esa misma narrativa, resulta fundamental destacar cómo esta investigación resalta los altos niveles de pobreza en el Triángulo Norte de Centroamérica, Honduras (65\%), Guatemala (54\%) y El Salvador (45\%), para relacionarlos con un líder regional 
en América Latina como Brasil que refleja unos niveles de pobreza cercanos al 42\%, tal y como remarcan los datos de la CEPAL.

Uno de los factores que coadyuvan los altos niveles de debilidad institucional lo podemos encontrar en la presencia y tráfico de ilícitos y estupefacientes en América Latina. UNODG muestra cómo las hectáreas cultivadas de cocaína han aumentado en la región, superando las 130.000 ha, permitiendo la producción de 671 toneladas de coca entre tres países: Colombia, Bolivia y Perú. Precisamente Colombia sigue ocupando una posición prominente en esta escala, con una tercera parte de la producción de coca en América Latina.

La posesión y presencia de armas de fuego provenientes del mercado negro y de las guerras civiles que han acontecido en el continente resulta fundamental a la hora de entender por qué países como Colombia, México, Brasil y los Estados que conforman el Triángulo Norte centroamericano lideran para la OEA una ominosa lista de Estados más inseguros. Cerca de ochenta millones de armas siguen presentes en las calles del continente latinoamericano, y están en manos de una sociedad civil con bajos niveles de educación.

El profesor de la Universidad EAN, Jerónimo Ríos Sierra, el Director Regional de la Organización de Estados Americanos, Ángel Martín Peccis, y el Decano de la Facultad de Gobierno y Relaciones Internacionales de la Universidad Santo Tomás, Alberto Castillo, formulan una tesis bajo la cual, si bien los índices de homicidios y procesamiento de drogas ilícitas resulta preocupante en la región, también existen datos alentadores que evidencian que los indicadores de violencia en América Latina tienden a reducirse cada vez más.

Empero, y pese a la presencia de datos que puedan dibujar una cartografía de la violencia e inseguridad más optimista, los 
propios autores resaltan cómo todavía América Latina ostenta el dudoso honor de poseer las ciudades más inseguras del planeta. De las 50 ciudades con una mayor tasa de homicidios por cada 100.000 habitantes, 40 pertenecerían a Latinoamérica. Brasil con 16 metrópolis, México con 9, Colombia con 5, Honduras con 2 y Guatemala y El Salvador con un centro metropolitano, concentran gran parte de esas elevadas tasas de homicidio.

Las reacciones nacionales y regionales ante tales tasas de homicidio, criminalidad e inseguridad han tendido a militarizar las operaciones, dejando de lado otro tipo de medidas sociales de tipo más preventivo. La militarización de la seguridad latinoamericana ha sido uno de los efectos más polémicos a la hora de contrarrestar el peso de grupos y bandas criminales que actúan en muchos casos bajo estándares transnacionales.

El Plan Colombia o la Iniciativa Mérida mexicana no han hecho sino aplicar medidas y mecanismos de políticas reactivas que asumen una lógica nacional westfaliana a la hora de solucionar problemas regionales. Los autores de este libro sostienen que las lógicas de fortalecer instancias y Estados-nación usando parámetros y mecanismos netamente reactivos no va a desembocar en una reducción de la violencia estructural regional a medio y largo plazo.

Los autores abogan por medidas y políticas sociales holísticas que puedan atajar y reducir los altos niveles de pobreza y desequilibrios sociales, que puedan fortalecer el Estado de Derecho y empoderar institucionalmente a las estructuras del Estado para poder luchar de esa manera contra la corrupción, al tiempo que permitir una armonización netamente latinoamericana de políticas públicas preventivas, dirigidas no tanto por sentimientos de soberanía nacional, sino más bien orientadas hacia una lógica 
supranacional y regional que permita una lucha descentralizada y regionalizada contra la violencia e inseguridad de América Latina.

El profesor Jerónimo Ríos cartografía en su capítulo la Política de Seguridad Democrática (PSD), que se implementó, stricto sensu, entre los años 2002 y 2006 en Colombia durante la primera presidencia de Álvaro Uribe Vélez, pero que tuvo su continuidad en su segundo periodo de gobierno entre los años 2006 y 2010. El capítulo desarrolla una hipótesis en la que se establece que la política de "mano dura" del presidente Uribe sublima la idea de paz negativa de Galtung y entiende la paz como una mera ausencia del conflicto, pero no como la implementación de condiciones sociales de tipo estructural y sistémico. Bajo estas premisas la política de seguridad de Álvaro Uribe no hizo sino vulnerar los principios básicos de la democracia, el Estado de derecho y llevar a cabo una constante violación de los derechos humanos. Ejemplo de esto fueron los casos de "falsos positivos".

Indudablemente, la Política de Seguridad Democrática tuvo un fuerte impacto en la reducción y debilitamiento de las estructuras armada y militar de las Fuerzas Armadas Revolucionarias de Colombia (FARC) y del Ejército de Liberación Nacional (ELN). Las FARC fueron debilitadas y reubicadas en zonas selváticas y montañosas, reduciendo su cuerpo de fuerza, al margen, de debilitar financiera y socialmente sus estructuras de poder.

Nadie duda de la capacidad que tuvo la PSD a la hora de agotar el proyecto guerrillero de las FARC y de aminorar las cifras de muertos provenientes de los combates con estos grupos insurgentes. Empero, si bien la mano dura del presidente Uribe resultó efectiva y eficiente a la hora de reducir hasta mínimos históricos el poder coercitivo de los grupos paramilitares e insurgentes, también lo es el 
hecho de que esta estrategia trajo consigno más sombras que luces. Las continuas vulneraciones de los principios democráticos, las aún no juzgadas violaciones de derechos humanos y la creencia de que con un hardpower iba a poner fin de manera sistemática a 50 años de conflicto, dejan entrever que el presidente Uribe y su PSD no tenían intención alguna de fomentar la tan anhelada paz social.

Atendiendo a ello se produce un estancamiento doloroso en el que tanto las FARC como el gobierno entienden que la victoria militar es la única manera de derrotar al enemigo. Interpretación que, por supuesto, resulta parcial y peligrosa ya que no entiende la resolución del conflicto en términos estructurales, sino solamente en términos de desintegración del oponente para acabar con una paz sin guerra.

Asimismo, podemos destacar el concepto y la teoría de la periferialización al que hace referencia dicho capítulo y que pretendería subvertir las estructuras de gobierno centralizadas en la capital colombiana, para así poder atender a una mejor redistribución de los presupuestos públicos entre la sociedad colombiana asentada en zonas periféricas. Este proceso pretende resultar fundamental para evitar tensiones, malestares y fracturas sociales y garantizar una paz positiva en la que incardinar el proceso de paz, desarme y desmovilización. Este hecho generaría una mejor óptica a la hora de resolver temas y heridas todavía abiertas como el de los escándalos de la parapolítica en los que se hicieron notorias y evidentes las connivencias políticas locales y regionales con el paramilitarismo.

La política militarista de Uribe dejó su impronta ya no solamente en la política nacional, sino también en política internacional. El asesinato de varios líderes paramilitares en territorio de Ecuador y Venezuela, con operaciones fuera de 
territorio colombiano, violando tratados internacionales en materia de soberanía nacional provocaron que tanto el presidente Rafael Correa, como el fallecido Hugo Chávez mantuvieran una serie de conflictos diplomáticos con sus vecinos colombianos.

A modo de conclusión, el autor asume también que si bien el PSD pudo debilitar y derrotar militarmente a las FARC y el ELN, el surgimiento y presencia de nuevas bandas criminales (Bacrim) han provocado que los niveles de violencia en el país no se hayan reducido drásticamente y que departamentos como Nariño, Arauca, Norte del Santander, Putumayo y otros departamentos de la cuenca del Pacífico, como Cauca, Valle del Cauca y Chocó tuvieran para 2010 unos índices de inseguridad y violencia preocupantes.

En otro de los capítulos más destacados el profesor Egoitz Antón destaca el panorama de polarización política extrema de Venezuela y establece un claro diagnóstico en el que la violencia física y política del país resulta desmesurada. El autor desglosa las causas y consecuencias de dicha violencia política y advierte que Venezuela está abiertamente enfrentada y dividida en dos focos de poder político bien diferentes y confrontados en los que no cabe sino más que un enfrentamiento ideológico.

Se destaca el movimiento socialista chavista que tuvo en Hugo Chávez una de las figuras latinoamericanas y venezolanas más destacadas de finales del siglo XX y principios del siglo XXI. Su legado reformista, revolucionario, contestatario a todas las políticas de Estados Unidos y que fomentó una nueva manera de entender la izquierda en América Latina alimentó un concepto de política social integrador y que fundó las bases para que la sociedad entendiese que el movimiento bolivariano era una manera de resolver los desequilibrios sociales, rebajar los niveles de pobreza y violencia, al 
tiempo que resolver una de las mayores crisis económicas que ha sufrido Venezuela en las últimas décadas.

Por otro lado, dentro de esa polarización antes mencionada, el grupo opositor parece estar conformado por unas élites políticas y económicas que buscan derrocar y contrarrestar las medidas del socialismo bolivariano de Hugo Chávez y de su sucesor, el actual presidente Nicolás Maduro. Precisamente las elecciones de 2013 significaron uno de los puntos más álgidos de enfrentamiento entre ambas facciones, ya que el líder opositor Henrique Capriles estuvo a unos miles de votos de haber conseguido la presidencia. Acusaciones de fraude electoral, violencia política y malversación económica sirvieron a Capriles para fomentar una campaña en la que se demandó la apertura del régimen chavista y la sublimación de la doctrina bolivariana del siglo XXI para poder dejar entrar en las estructuras de poder a las élites económicas.

Las elecciones de 2019 no suponen sino el fin último al que se agarran tanto Henrique Capriles y la oposición venezolana y de esa manera cerrar con el ciclo político socialista bolivariano al que se ha asimilado Venezuela en las últimas décadas. La violencia callejera, la inseguridad y la polarización social a la que ha llegado el país han provocado que dicha polarización política se haya transformado en una tensión social que requiere de una acción colectiva. Las protestas en la calle, medios de comunicación, alentadas por las fuerzas económicas durmientes en el país van encaminadas a deslegitimar al régimen del presidente Nicolás Maduro y hacer implosionar al movimiento bolivariano.

Por último, otro de los capítulos más destacados es el que el profesor de Ciencias Políticas de la Universidad Complutense de Madrid, Fernando Harto de Vera, escribe sobre los conflictos en Centroamérica y especialmente en el Triángulo del Norte antes 
mentado. Harto de Vera hace un repaso de los conflictos violentos que acontecieron en la década de 1980 en la región para concluir en un detallado análisis de los altos índices de homicidios y pobreza que se suceden en Honduras, Guatemala y El Salvador en la actualidad.

La confluencia de tres tipos de conflictos en los años 80 en la región centroamericana, por un lado las guerras civiles de Guatemala, El Salvador y Nicaragua, por otro, los conflictos regionales en el Bloque de Tegucigalpa (Costa Rica, El Salvador y Honduras frente a Nicaragua) y, por último, el conflicto entre Estados Unidos y el régimen Sandinista contra Nicaragua dejaron no solamente un saldo de casi 400.000 muertos, sino un estado de tensiones políticas sociales y económicas que han fomentado y cristalizado un estado de emergencia en la región centroamericana.

Si bien los Acuerdos de Esquipulas II (1987), los Acuerdos de Chapultepec (1992) o los acuerdos entre el gobierno sandinista y la guerrilla nicaragüense de 1988 resultaron fundamentales para poder pacificar y estabilizar la región, parece que no pudieron atemperar totalmente el fenómeno de la violencia e inseguridad que vive Centroamérica en la actualidad. Fernando Harto establece una brillante cuantificación del fenómeno, con el fin de discernir las causas exactas que provocaron que las tasas de homicidio en el Triángulo del Norte sean las más elevadas en el mundo.

Las respuestas reactivas de Seguridad Humana y Seguridad Democrática polarizan las teorías presentes para tratar de atajar la violencia. Esa oscilación entre políticas militares reactivas o políticas integrales de tipo social son precisamente las que -según Harto de Vera- deben compensar la violencia de la región centroamericana, atendiendo, sobremanera, al fracaso de las políticas de represión y endurecimiento de las políticas de seguridad regionales. 